\title{
ESTRATEGIAS PARA MOVILIZAR LA IGLESIA AL TRABAJO DE EVANGELISMO
}

\author{
Benitez, Joel \\ jgj.36@hotmail.com \\ Seminario Teológico Adventista de Venezuela
}

Fecha de recepción: Noviembre 2013

Fecha de aceptación y versión final: Junio 2014

Debido a la gran necesidad emergente del cumplimiento de la misión y a la gran masificación urbana, se siente el compromiso ferviente por lograr alcanzar a otros con efectividad. Dios ha dejado recursos disponibles esenciales y la iglesia tiene la responsabilidad de usarlos, para lograr impartir el mensaje de salvación al mundo. Pero cada día el desafío es mayor, pues los paradigmas cambian, los presupuestos deben incrementarse y el enemigo de Dios ataca con mayor intensidad. El mundo, debido a sus necesidades, espera por una iglesia activa y consecuente con su mensaje, pero tristemente la iglesia se encuentra en un letargo o en peores casos a perdido de vista su misión. Este artículo expone los problemas más recurrentes, las necesidades elementales de la iglesia y las estrategias para romper con la apatía y el desanimo, con lo que se espera ayudar al liderazgo de la iglesia a cumplir con los planes de movilización.

Palabras claves: Evangelismo, emergente, estrategias, iglesia. 


\section{STRATEGIES TO MOBILIZE THE CHURCH TO THE WORK OF EVANGELISM}

Summary:

Due to the large emerging need to accomplishment the mission and great urban overcrowding, and the passionate commitment to reach effectively others. It is necessary to remember, that God has gave it essential resources and the church has the responsibility to use them to achieve impart, the message of salvation to the world. But every day the challenge is greater, since the paradigms change, budgets should be increased and the attack of enemy of God is with greater intensity. The world, due to their needs, wait on for an active and consistent church with her message, but sadly the church is in lethargy or worse seems that lost sight of its mission. This article describes the most common problems, the basic needs of the church and strategies to break the apathy and discouragement, with which is expected to help the church leadership to meet mobilization.

Keywords: Evangelism, pop, strategies, church. 


\section{Estrategias para movilizar a la iglesia al trabajo de evangelismo}

Necesidades del mundo hoy:

En la actualidad, vivimos en un mundo que muchas veces es frio, insensible e indiferente. No es de maravillarse entonces, que cuando mostramos genuino amor y consideración hacia los demás, sin que nada especial nos mantenga ligado a ellos, se inquieten y se sorprendan adecuadamente.

La iglesia deberá ser un refugio donde la gente golpeada encontrara cura y restauración en Cristo y su pueblo.

Lo que debe animarnos, es saber que cuando abandonamos el yo y nos concentramos en Cristo, cuando caminamos y trabajamos con él, nos damos cuenta que no necesitamos preocuparnos por los resultados. Ofrezcamos el agua de vida a un mundo sediento. Hagamos resaltar su sabor y vitalidad en este planeta. Esto significaría darnos a nosotros mismos en servicio a otros. $^{1}$

1 Philip G. Samaan, El método de Cristo para testificar (Bogotá: APIA, s/f), 13-70.
Factores que inciden en la poca movilización:

1. Mediocridad de nuestro compromiso con el evangelio. No vive por y para el evangelio. No respiran el evangelio. No es la principal motivación de sus vidas y no evangelizan.

2. Desconocimiento de las responsabilidades Evangelística. Representa una indiferencia ante sus intereses en nuestro mundo. ${ }^{2}$

3. Por falta de conocimiento. Falta de entendimientos claros y de evidencias históricas.

4. Por miedo a la gente. Son tímidos y temen ser rechazados.

5. Por un espíritu derrotista. Piensan que todo depende de ellos, y que por lo tanto es inútil trabajar. La obligación se deriva de la necesidad de glorificar a Dios en la proclamación.

2 "Tener buenas nuevas y no compartirlas es un egoísmo imperdonable" (Manual de evangelización David Burd) 
6. Falta de plenitud espiritual. Ausencia del poder del Espíritu en la vida del creyente. ${ }^{3}$

Esto habla de por lo menos tres miedos importantes que enfrenta la comunidad de creyentes: miedo a la insuficiencia, miedo al rechazo, miedo al fracaso. Este enfoque es presentado por Medill. En el libro palabras de vida del gran maestro, Elena G. De White dice:

"Están trabajando por el bien de otros; sus deberes apremian, sus responsabilidades muchas y permiten que su trabajo ocupen hasta el tiempo que deben a la devoción. Descuidan la comunión que debieran sostener con Dios por medio de la oración y el estudio de la palabra... anda lejos de Cristo, su vida no está saturada de su gracia y se revelan las características del yo. Su servicio se echa a perder por el deseo de supremacía y el trato áspero y falto de bondad del corazón insubordinado. He aquí

3 David Burd, Manual de evangelización (Barcelona: Editorial Clie, 1999), 9-18. uno de los principales secretos del fracaso en la vida cristiana. ${ }^{4}$

La campaña a favor de las almas que se han ido de la iglesia y aquellas que están resfriadas en la fe, no debe ser muy complicadas, pero si profundamente espiritual. Mientras que el mundo muere sin haber sido alcanzado por el mensaje de salvación, la iglesia sigue esperando que solo el pastor o el director misionero realicen una obra que Dios encomendó a toda la iglesia.

Además, se perciben tres problemas puntuales que se presentan desde el mismo comienzo de la conversión. Esta son necesidades puntuales:

1. Como saber si soy salvo.

2. Como relacionarse con el mundo, los amigos y la familia.

3. Como evitar recaer en el pecado. ${ }^{5}$

4 Elena G. de White, Palabras de vida del gran maestro (Buenos Aires: ACES, 1999), 32.

5 José Fuentes, Pasos para llegar a las almas (Mountain View: Pacific Press Publishing Association, 2002), 16-45 


\section{Necesidad emergente la iglesia hoy}

Debemos ser realistas, los tiempos han cambiado, el futuro es incierto. La desorientación y la desesperación son características de nuestra época. La gente busca algo real.

No se dejan engañar por individuos piadosos que viven de apariencia. Las respuestas cristianas deben ser aplicables. Se necesita la solución realista a problemas específicos.

Debemos conocer la condición de los que están a nuestro alrededor. Que piensan, que sienten y que aspiran. Demostrar a nuestros conocidos que los creyentes nos interesamos en los asuntos de este mundo.

Debemos relacionarnos en base al contacto personal.

Es necesario tener cuidado con la fe ambiental: tipo de vida que surge y depende de nuestro ambiente. $\mathrm{O}$ sencillamente, nos inclinamos en la perspectiva de ser cristianos por deslizamiento: estos cantan de experiencias cristianas gloriosas como si fueran suyas.
Mayormente tendemos a aceptar como norma una tendencia irreal.

Recordemos la tendencia en ciertos datos no es suficiente: puede que creamos algunos datos sobre Jesucristo en vez de relacionarnos dinámicamente con la persona de los datos.

No hay nada más importante que ser sincero: no levantemos una fachada para impresionar a otros. El evangelio nos parece menos real cuando no vemos evidencia de su poder redentor. ${ }^{6}$

A través de los días, la pregunta emergente radica en cuál es la necesidad imperante indispensable para completar la tarea de proclamar el mensaje. A lo mejor no nos falte nada, tenemos dinero, tiempo, estructura eclesiástica eficaz, un programa brillante y un mensaje bello en la persona de Cristo. Quizás lo que nos está faltando sea el hombre (Ez. 22:30), el creyente lleno de entusiasmos para avanzar en la tarea.

6 Paul E. Little, Como compartir su fe (El Paso, TX: Casa bautista de publicaciones, 1978), 7-24. 
Ganar almas es el centro del ministerio y si el ministro que está envuelto en su tarea ministerial no le queda tiempo para salvar almas, tampoco debiera tener tiempo para ser ministro.

Más que tratar con temas de la hora, debemos tratar con temas de la eternidad.

El evangelismo sin adecuado contenido teológico, pronto degenera en sentimentalismo, emocionalismo o retorica.

El gran enemigo audaz de la iglesia es la Apatía.

El deseo de reconocimiento y aceptación empuja a la iglesia a los rincones del formalismo con apariencia de liturgia. Falta de mucha fuerza espiritual.

Dormimos y la voz de Dios no se oye y el reavivamiento y el poder tardan en llegar.

Como estructura eclesiástica, podemos trazar planes y seleccionar estrategias, pero Dios tiene la suma de poder y la puede conceder a su iglesia. Debemos depender de él, ya que hoy dependemos de nosotros mismos. ${ }^{7}$

7 Salim Japas, Llama divina (Bogotá: Asociación Publicadora Interamericana,
Un factor de gran importancia es que el obrero sea la persona adecuada para la obra que ha de realizar. La gente oye y ve a Cristo a través de sus embajadores.

Pablo tuvo que seleccionar las comunidades donde iría a predicar el evangelio. ${ }^{8}$

La mente centrada en Cristo (fruto de honda reflexión, gana almas). La iglesia no puede evangelizar sino está segura de su evangelio. Eso sería una pérdida de fe dinámica.

No deben tratar de minimizar los logros del hombre a fin de ver la importancia del evangelio. La sinceridad no basta, debe ir acompañada de la entrega. Como cristiano nos corresponde vigilar hacia donde nos encaminamos. ${ }^{9}$

Según el Misiologo adventista: Gottfried Oasterwal existen 5 objetivos importantes que la iglesia debe tener:

1. La iglesia es un instrumento, no es objetivo de

1989) 1-59.

8 Moisés Mariscal, Abriendo Caminos a la evangelización (Barcelona: Clie, 1996) 27-34

9 Ibíd., Salim Japas, llama divina. 
la actividad divina. No se concentra en si misma sino en la misión de Dios.

2. La iglesia debe crecer en santidad y amor, en compañerismo y fe, en gracia y conocimiento de Cristo.

3. Fue organizada para servir en palabra y obras.

4. Su participación en la gran controversia entre el bien y el mal será cada vez mayor.

5. Su actividad redentora será completa cuando se envuelva y se comprometa con la totalidad de su ser y con la totalidad de su matrícula.

Ahora, la evangelización es el impacto que el Espíritu Santo hace en los corazones humanos a través del evangelista.

Implica tener capacidad de adaptarse. Según Niles: es un mendigo enseñando a otro mendigo a encontrar pan.

La obra completa exige que esos hombres y mujeres sean confirmados y enseñados en la verdad presente.

El cristiano debe tener inamovible convicción, intensa compasión e indivisa consagración (ejemplo: Pablo).

La relación intima con el Señor aglutinada por el amor, puede darnos la mayor motivación para el avance. La mayor virtud consiste en hacerlo. Calidad y cantidad debe ir unida en el avance.

Nuestro carácter cristiano es convincente.

\section{Factores que deben mo- vernos a la predicación:}

1. Tenemos un mensaje divino que comunicar.

2. Existe una gran necesidad de conocimiento de Dios en la población urbana.

3. Los creyentes deben recibir una adecuada preparación para ser testigos eficientes del mensaje.

4. Aceptar que el mensaje de Cristo o su exaltación es el secreto del éxito.

5. El Espíritu Santo hace po- 
sible que nuestro esfuerzo cobre significado y vida.

6. Consagración completa y sincera al servicio de Dios.

7. Debe la mayor parte de la iglesia trabajar en conjunto con Dios.

8. La ambición del creyente es investigar la biblia.

9. La autoridad está en la biblia.

10. Teología y evangelismo nunca aparecen separadas en la biblia.

\section{¿Qué hacer entonces con el estancamiento?:}

1. Debiéramos confesarlo a Dios y a nosotros mismos.

2. Debiéramos tomar tiempo para pasar un inventario espiritual(a solas con Dios y la biblia).

3. Conviene buscar ayuda de un amigo cristiano donde encuentre franqueza, oración y preocupación.

4. Descubrir si el fruto del estancamiento es fruto de la fatiga o monotonía.

Recuerde la vida que no se somete a examen, la senda que no se somete a escrutinio, es engañosa e indigna del cristiano.

La disciplina del tiempo se convierte hoy en día en un deber cristiano primordial, fijar prioridades, planear programas en cumplimiento dentro de la flexibilidad del Espíritu Santo.

No tratamos de inventar un plan, sino de descubrir la estrategia de Dios. No debemos confundir estrategia con táctica ya que la estrategia conlleva visión.

Entonces la evangelización total conlleva: metas, agentes y métodos. Esto es poner en nuestra mente el vasto mundo.

Si nuestra meta es penetrar al mundo, nuestra primera tarea es movilizar a la iglesia para que proporcione los agentes necesarios para lograr lo que desea.

Nuestra meta no es el triunfo total. Recordemos la predicación es la responsabilidad de toda la iglesia. ${ }^{10}$

10 Leighton Ford, La gran minoría. (Miami: Editorial Caribe, 1969) 1-45. 
Necesidades practicas del creyente candidato a discípulo

Si el creyente recibe atención personal, comprometida, cuidadosa llegara a ser el hombre y la mujer de Dios que podrá servir.

El discipulado es el método óptimo para alcanzar a nuestro mundo para Dios.

Los discípulos crecen a la imagen de Cristo.

Los discípulos reproducirán la calidad de sus valores en otros. Solo los creyentes maduros pueden impactar al mundo hoy. La reproducción y multiplicación espiritual ocurre cuando un discípulo pasa a otros la calidad de sus vidas en Cristo.

No todos están dispuestos a pagar un precio tan alto, por eso Cristo reto a todos a que calcularan el precio. Esto desafía a dar absoluta prioridad a Cristo en su vida.

\section{Precio a pagar por el discípulo:}

1. Le amasen a él antes que a otra cosa (Lc 14:26)
2. Se negasen a sí mismo (Mt 16:24)

3. Tomasen su cruz (Mt $16: 24)$

4. Le siguiesen (Lc 14:27)

5. Renunciar a todo (Lc $14: 33$ )

Viendo que el precio es tan alto del discipulado que Jesús enfatizo, no extraña que no empezasen un movimiento de masas, sino que recluto a unos po$\cos$ que fueron profundamente comprometidos con él.

Esos pocos fueron suficientes para cambiar el mundo.

Esto arroja aspectos básicos esenciales que todo discípulo debe tener: amor a Jesús, hambre espiritual, aptitud dispuesta a aprender, fidelidad, deseo de sacrificar tiempo, fuerza y hasta las relaciones. ${ }^{11}$

Una herramienta necesaria es un testimonio personal claro y eficaz. Solo la experiencia que ha tenido el cristiano con respecto a la fidelidad de Dios es la sustancia de su testimonio.

11 Gunter Krallmann, Siguiendo a Jesús (Barcelona: Clie, 1986) 9-17. 
Hoy hay que hacer hincapié en los beneficios positivos del evangelio..$^{12}$

La esperanza de ganar este mundo para Cristo existe en poder organizar y establecer fuerte iglesias misioneras, Evangelística según el concepto del Nuevo Testamento.

La persona salva debe ser estimulada a estudiar y practicar el arte de ganar almas, para que puedan ser obedientes en esta parte tan importante de su servicio al Salvador.

La iglesia como la conocemos en el mundo no es eterna, pero ha sido organizada para servir, para apresurar la venida de Cristo; pero los cristianos que forman las iglesias tienen la promesa de la vida eterna. ${ }^{13}$

12 James Kennedy, Evangelismo explosivo (Maracaibo: editorial libertador, 1975) 78-84.

13 Roy Lyon, Evangelismo según la gran comisión (El Paso, Tx: Casa Bautista de Publicaciones 1967) 69-78.
El triple sentido de misión de un discípulo

1. Un sentido de gratitud: lo hacen impulsados por la maravillosa experiencia de amor de Dios a través de Jesús.

2. Un sentido de responsabilidad: vivir vidas consecuentes con la profesión que han hecho. Estaban dispuestos a agradar a Dios. El cristiano sabe desde el comienzo que por medio de la gracia de Dios será salvo a menos 75 que apostate de su salvador.

3. Un sentido de preocupación: nadie puede erigirse como bondadoso delante de Dios.

4. 2 posibilidades abiertas al hombre: puede compartir la vida divina a través de la relación con Jesús o permanecer espiritualmente muerto. ${ }^{14}$

14 Michael Green, La evangelización de la iglesia primitiva (Argentina: Ediciones Certeza 1979) 77-124. 
Experiencia de los discípulos después de la muerte de Jesús:

Los discípulos tenían el conocimiento pleno de su misión. Estaban convencidos de lo que debían hacer y la manera de cómo debían realizarlo. Habían palpado los gloriosos resultados del cumplimiento de la misión de su maestro, visto y experimentado el poder que había en el mandato divino.

Luego de que Cristo desaparece del escenario, aquellos discípulos seleccionados, comisionados, autorizados para con76 tinuar la obra de su maestro, dejaron de lado su grandiosa responsabilidad.

Se olvidaron de la razón primordial de su existencia y momentáneamente se desatendieron de la misión. En vez de salir e identificarse con la causa de su maestro se asustaron y se escondieron llenos de temor.

Un espíritu de confusión, lobreguez e incertidumbre se apodero de ellos. La tristeza y la depresión arropo sus mentes.

\section{Método de reenfoque y movilización de Jesús}

1. Cristo se acerca a ellos para despertarlos de su lúgubre sueño y sacarlos de su profunda depresión. (Lucas 24:46)

2. Les recuerda que el murió para que con su poder su iglesia pudiera dar cumplimiento al cometido que en el pasado se coloco sobre el pueblo.

3. El cristiano puede estar entretenido y enredado en asuntos secundarios e irrelevantes.

4. Es posible que los ojos se deslumbren tras programas y actividades que distraen la atención de la verdadera misión.

5. Las crisis mundiales lo hacen olvidar la razón de ser.

6. Los seguidores de Jesús no han sido llamados para dedicarse a luchar por mejores condiciones sociales, políticas y económicas en esta tierra. 
7. Cada cristiano debe convertirse en el promotor, defensor y reclutador potencial de personas.

8. Debe mantener la mirada en Cristo, centrarse en los intereses del país de la ciudadanía cristiana $(\mathrm{Ca}-$ naán).

9. Las palabras de Cristo provocaron un nuevo compromiso con la misión que se les había dado. ${ }^{15}$

\section{Estrategias para} movilizarlos a trabajar

Abraham Lincoln dijo en 1858:

"Si antes que nada pudiéramos saber donde estábamos y hacia dónde vamos, podríamos juzgar mejor que debemos hacer y cómo debemos hacerlo"

La gente no planea para fracasar, fracasa al planear. Es necesario establecer metas para atender. Estas pueden ser algunas de ellas:

15 Filiberto Martínez Páez, Dilo como puedas, pero dilo (Santo Domingo: $\mathrm{S} / \mathrm{D} ; 2005)$ 15-24.
1. Seguridad de salvación y permanencia en Cristo.

2. Coherencia en las cosas fundamentales (aplicación de muchas verdades fundamentales de cómo crecer en Cristo). Vida devocional disciplinada.

3. Estabilidad en doctrinas básicas (sólido fundamento).

4. Desarrollo de la semejanza con Cristo (desarrollo del fruto del Espíritu en la vida del creyente).

5. Aplicar de forma personal la palabra de Dios y obtener sus beneficios (creciente independencia en la vida).

6. Reproducir metas previas en la vida de otras personas (producción de multiplicadores). ${ }^{16}$

7. Debe asumirse con seriedad la predicación.

8. Estudiar la palabra. Preparar el mensaje adecuadamente antes de predicarlo.

16Gary W. Kunne, Dinámica del evangelismo (Barcelona: Clie, 1977) 95 -125. 
9. El pueblo necesita comida y no una receta.

10. Tenemos que conocer el mensaje y conocer el pueblo.

11. Los creyentes victoriosos son los que logran que el fuego siga ardiendo sobre el altar del entusiasmo. Dios espera autenticidad.

12. La fuerza vivificante de la iglesia es medida por su disposición a vivir en koinonia y por la disposición de proclamar el kerigma.

13. Somos hombres limitados a causa de nuestra caída, pero el poder de Cristo ha vencido.

14. Mi pulpito tiene ruedas y va donde la necesidad existe. $^{17}$

15. Si podemos instruir al creyente cristiano a ganar al menos un alma para Cristo cada año, habremos iniciado la marcha hacia la victoria.

16. Debe usarse todos los recursos que la tecnología trae a la iglesia.

17 Ibíd. Salim Japas, Llama divina.
17. Evaluación madura de los resultados conducirá a la autoevaluación de la metodología.

18. Es necesario que los creyentes comiencen a testificar bajo un primer impulso dado divinamente en términos generales, antes de saber con exactitud donde y cuando Dios piensa obrar.

19. Las dificultades son la brújula correctora del rumbo en la actividad misionera.

20. Hay que continuar perseverando en busca de la voluntad de Dios, mientras continúan activos. ${ }^{18}$

21. El caos deriva de la falta de respeto a la palabra de Dios.

22. Debemos despertar interés en la misión. El impacto de la acción esta en el mero hecho de hablar. Nuestra aptitud hacia otros, el modo de reaccio-

18 Ibíd. Moisés Mariscal, Abriendo caminos a la evangelización (Barcelona: Clie, 1996) 27-34. 
nar ante las circunstancias, esa paz y contentamiento que nos sostiene en las presiones y crisis de la vida, será un indicio de la calidad de nuestra vida.

23. Al desarrollarse en nosotros una confianza en que el Espíritu Santo nos ha de guiar a las personas interesadas, podemos sobreponernos a la tendencia de pedir disculpa por nuestra fe.

24. Enseñarle al discípulo que no debe ir demasiado lejos. Debe presentar el mensaje, solo a lo que el otro está dispuesto a recibir y no condenarle.

25. Nunca condenar a nadie. Deben aprender el arte del elogio sincero.

26. No desviarse del tema principal: no permitir que los asuntos secundarios nos perturben. Mantener lo importante.

27. Debemos enfrentar a la gente con Cristo.

28. Se debe recalcar que nunca debe seguirse a la ma- yoría por obligación.

29. Se debe expresar mucho amor y comprensión. ${ }^{19}$

30. Comencemos de inmediato a trabajar.

31. Empeño en lo encomendado, oremos mientras hablamos a otros.

32. Se debe comprender el valor de las almas.

33. Jamás podremos elevar a nadie por sobre el nivel en que nos encontramos nosotros.

34. Debemos procurar conducirse rectamente, no debemos causar oprobio al Señor por nuestras palabras, nuestros actos $\mathrm{O}$ apariencias.

35. Ser un hombre o mujer de oración: es la fuerza que abre todas las puertas, quita todas las barreras. La iglesia marcha sobre las rodillas.

36. Debe desplegar mucho tacto.

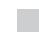


37. No debe pensar que su labor ha terminado cuando lleva un alma a los pies de Cristo.

38. Si un alma no acepta, no pares. No se ha terminado la responsabilidad.

39. Aunque aparentemente fracase no habrá daño alguno.

40. No deben sentir temor. ${ }^{20}$

41. En el presente, la iglesia se ve alejado de la koinonia casi completamente, limitando las actividades de testificación de la iglesia exclusivamente a la proclamación: esta manera ha logrado 2 cosas simultáneas: quitar el mayor resguardo para la salud interna de la iglesia y debilitar su testimonio efectivo delante del mundo.

42. Sin la simpatía de Cristo en nuestra vida y sin sentir la misma compasión de él, nuestro testimonio

20 Myer Pearlman, El evangelismo personal (Miami: Editorial vida 1959) 3-31

llega a ser una formalidad, un deber desprovisto de calor, vitalidad y poder. $^{21}$

"no debiera haber demora en estos esfuerzos bien planeados para educar a los miembros de la iglesia"22

"Muchos miembros de la iglesia que profesan tener un conocimiento de la verdad presente, no saben bien lo que creen, $y$ por lo tanto no pueden defender o testificar por su fe. La mayor ayuda que pueda darse a nuestro pueblo consiste en enseñarle a trabajar para Dios y a confiar en él, y no en los ministros"23.

Renueve su compromiso con Dios y entregue su vida al Señor antes de salir de su casa cada mañana.

No entretenga su mente repasando o evocando las experiencias, tentaciones y problemas del pasado; utilize esa energía para

21 Ibíd., Philip G. Samaan, (Miami: Apia, 2003), 13-70

22 Elena de White, Testimonio para la iglesia (Miami: Apia, 2003), 9:119

23 Elena de White, Joyas de los testimonios (Miami: Apia, 2000), 3:82 
lidiar con actividades saludables.

Planee su vida teniendo un punto de referencia. No limite sus blancos a las experiencias limitadas e imperfectas de la vida.

\section{Leyes de crecimiento esencial:}

1. Ley de la relación: relación con Dios íntima y permanente.

2. Ley del compromiso: base de todo avance.

3. Ley de la concentración: colocar las cosas en la lista, según la prioridad.

4. Ley del amor hermanable: clima hermanable lleno de afecto y comprensión.
5. Ley de la espera: saber esperar en activa vigilancia, anticipa el crecimiento. ${ }^{24}$

Todas estas estrategias nos apuntan a una conexión intima y personal con Jesús, tener un sentido de misión y avanzar por la fe en procura de ganar a otros para el reino celestial. Es conocer las estrategias de Dios y hacerlas vivencial en nuestras vidas. Es vivir un reflejo de Jesús.

Cada esfuerzo dedicado, cada momento apartado será de gran bendición en la obra fiel en pro de nuestros semejantes. Nada está perdido si nos entregamos enteramente al maestro.

24 Ibíd. Salim Japas, Llama divina. 